\title{
Regionally-Specific Diffusion Tensor Imaging in Mild Cognitive Impairment and Alzheimer's Disease
}

\author{
M.M. Mielke, N.A. Kozauer, K.C.G. Chan, M. George, J. Toroney, M. Zerrate, K. Bandeen- \\ Roche, M-C Wang, P. vanZijl, J.J. Pekar, S. Mori, C.G. Lyketsos, and M. Albert \\ Departments of Psychiatry, Neurology and Radiology, Johns Hopkins University School of, \\ Medicine; the Department of Biostatistics, Johns Hopkins University Bloomberg School of, Public \\ Health; and the F.M. Kirby Center on Brain Imaging at the Kennedy Kreiger Institute, Johns Hopkins \\ University
}

\begin{abstract}
Background-Diffusion tensor imaging (DTI) studies have shown significant cross-sectional differences among normal controls (Bozzali et al., 2002), mild cognitive impairment (Robbins et al.) and Alzheimer's disease (AD) patients in several fiber tracts in the brain, but longitudinal assessment is needed.
\end{abstract}

Methods-We studied 75 participants (25 NC, 25 amnestic MCI, and 25 mild AD) at baseline and 3 months later, with both imaging and clinical evaluations. Fractional anisotropy (Bozzali et al., 2002) was analyzed in regions of interest (ROIs) in: (1) fornix, (2) cingulum bundle, (3) splenium, and (4) cerebral peduncles. Clinical data included assessments of clinical severity and cognitive function. Cross-sectional and longitudinal differences in FA, within each ROI, were analyzed with generalized estimating equations (GEE).

\begin{abstract}
Results-Cross-sectionally, AD patients had lower FA than NC ( $\mathrm{p}<0.05)$ at baseline and 3 months in the fornix and anterior portion of the cingulum bundle. Compared to MCI, AD cases had lower FA $(p<0.05)$ in these regions and the splenium at 0 and 3 months. Both the fornix and anterior cingulum correlated across all clinical cognitive scores; lower FA in these ROIs corresponded to worse performance. Over the course of 3 months, when the subjects were clinically stable, the ROIs were also largely stable.
\end{abstract}

Conclusions-Using DTI, findings indicate FA is decreased in specific fiber tracts among groups of subjects that vary along the spectrum from normal to $\mathrm{AD}$, and that this measure is stable over short periods of time. The fornix is a predominant outflow tract of the hippocampus and may be an important indicator of $\mathrm{AD}$ progression.

\section{Introduction}

Diffusion tensor imaging (DTI), a relatively new magnetic resonance imaging procedure, was developed to examine the integrity of white matter fiber bundles in the nervous system (Basser and Jones, 2002; Beaulieu et al., 1996; Mori et al., 1999) by measuring fractional anisotrophy (FA) (Bozzali et al., 2002) and mean diffusivity. It can be used to assess the degradation of

CORRESPONDING AUTHOR: Michelle M. Mielke, Ph.D., Assistant Professor, Johns Hopkins University School of Medicine, Department of Psychiatry, Division of Geriatric Psychiatry and Behavioral Sciences, Bayview - Alpha Commons Building, $4^{\text {th }}$ floor room 454, Baltimore, MD 21224, Phone: 443-326-5174, Fax: 410-550-1407, E-mail: E-mail: mmielke1 @jhmi.edu.

Publisher's Disclaimer: This is a PDF file of an unedited manuscript that has been accepted for publication. As a service to our customers we are providing this early version of the manuscript. The manuscript will undergo copyediting, typesetting, and review of the resulting proof before it is published in its final citable form. Please note that during the production process errors may be discovered which could affect the content, and all legal disclaimers that apply to the journal pertain. 
white matter tracts in the brain, and has therefore been applied to the study of a variety of neurodegenerative disorders, such as Alzheimer's disease (AD).

Using DTI, a number of studies have reported reduced FA and/or increased mean diffusivity in patients with established AD, compared to normal controls (Bozzali et al., 2002), within the splenium of the corpus callosum (Bozzali et al., 2002; Duan et al., 2006; Naggara et al., 2006; Rose et al., 2000; Sydykova et al., 2007) and the cingulum bundle (Cho et al., 2008; Ding et al., 2008; Fellgiebel et al., 2005; Fellgiebel et al., 2008; Takahashi et al., 2002; Zhang et al., 2007). DTI studies of white matter integrity within several cortical regions have also shown differences between patients with AD and controls (Bozzali et al., 2002; Choi et al., 2005; Fellgiebel et al., 2004; Medina et al., 2006; Naggara et al., 2006; Stahl et al., 2007; Takahashi et al., 2002).

A small number of studies have also used DTI to assess subjects with mild cognitive impairment (MCI) (Petersen, 2004; Petersen et al., 1999). Individuals with amnestic MCI have an increased risk of progressing to $\mathrm{AD}$ (Petersen and Morris, 2005), and recent studies indicate that the majority of amnestic MCI cases have AD pathology in their brains on autopsy (Bennett et al., 2005; Jicha et al., 2006). The DTI studies have demonstrated reduced FA and/or increased mean diffusivity in MCI cases relative to NC in the cingulum bundle (Zhang et al., 2007) and the splenium of the corpus callosum (Cho et al., 2008; Stahl et al., 2007). Differences in white matter integrity from selected cortical regions has also been reported in MCI cases compared to controls (Fellgiebel et al., 2004; Huang and Auchus, 2007; Stahl et al., 2007).

These findings suggest that FA in the cingulum bundle and splenium may be useful for assessing the evolution of disease as $\mathrm{AD}$ progresses. This is particularly important because of the continuing need to identify biological measures that can accurately assess the early progression of ongoing pathological change and, therefore, speed drug development for both prodromal and established AD. However, longitudinal DTI studies are necessary to understand the reliability of these measures over time, and their relation to change in clinical status, in order to determine whether DTI measures may be useful biomarkers of AD.

As part of an ongoing longitudinal study examining the utility of DTI as a biomarker of AD progression, the aims of the present analyses were to: (1) examine cross-sectional differences in FA, among a group of cognitively NC, and subjects with amnestic MCI and AD; (2) to examine the short-term stability of these measures between baseline and 3 months; and (3) to examine the relationship between FA in the regions of interest and assessments of cognitive status in the subjects. Regions of interest included ones that have been used in previous DTI studies of $\mathrm{AD}$ and MCI cases, specifically the corpus callosum and the cingulum bundle. A measure of the fornix was also included as one previous study that looked at asymptomatic individuals with a dominant genetic mutation for $\mathrm{AD}$ reported abnormalities in this region (Ringman et al., 2007). We hypothesized that there would be reductions in FA for the fornix, cingulum and splenium in AD compared to $\mathrm{MCI}$ and controls and that FA in these regions would remain stable over the 3-month follow-up.

\section{Methods}

\section{Subjects}

Participants were primarily recruited from two sources: the Johns Hopkins Alzheimer's Disease Research Center and memory clinics associated with Johns Hopkins Hospital. Three groups of subjects were recruited: (1) Normal Controls (Bozzali et al., 2002): subjects who were cognitively normal and had a Clinical Dementia Rating (CDR) of 0 (Hughes et al., 1982; Morris, 1993); (2) Mild Cognitive Impairment (Robbins et al.): subjects who were nondemented but had mild memory problems, had a $\mathrm{CDR}=0.5$, and met criteria for amnestic MCI, 
single or multiple domains impaired (Petersen, 2004); (3) Alzheimer's disease (AD): subjects who had mild AD, had a CDR=1, and met NINCDS/ADRDA criteria for AD (McKhann et al., 1984).

Subjects were excluded from enrollment if they were under the age of 55, had a history of a neurological disease other than AD or a history of major psychiatric illness. Subjects were required to have an informant who could provide information about their daily function.

All subjects provided informed consent prior to the initiation of the study in accordance with the requirements of the Johns Hopkins Institutional Review Board. Consent procedures followed the guidelines endorsed by the Alzheimer's Association for participation of cognitively impaired individuals (Alzheimer's Association, 2004). Eighty participants met the initial inclusion criteria and were consented. However, four were not able to tolerate the MRI and one was found to be too impaired based on the baseline neuropsychological examination, leaving a total of 75 participants: $25 \mathrm{NC}, 25 \mathrm{MCI}$, and $25 \mathrm{AD}$.

\section{Study Design and Assessments}

As part of an ongoing study, participants are evaluated four times over the course of a year: at 0, 3, 6 and 12 months. Each visit includes a clinical assessment, a neuropsychological examination, and an MRI scan. Blood specimens are also obtained for later analysis. The present report describes the findings from the first two visits. The clinical assessment consisted of : (1) a medical, psychiatric and neurologic history; (2) a medication inventory; (3) a physical and neurological examination; and (4) a psychiatric examination consisting of the Geriatric Depression Scale (Yesavage et al., 1982) and the Neuropsychiatric Inventory (Cummings et al., 1994). The degree of clinical severity of each subject was evaluated by a semi-structured interview (Hughes et al., 1982; Morris, 1993). This interview generates both an overall CDR rating and a measure known as the CDR Sum of Boxes (CDR-SB). The neuropsychological battery consisted of eight tests and included: (1) two tests of global cognitive function: the Mini-Mental State Exam (Folstein et al., 1975) and the Alzheimer's Disease Assessment Scale - cognitive portion (ADAS-Cog) (Mohs et al., 1997); (2) three tests of episodic memory: the California Verbal Learning Test (CVLT) (Delis et al., 1988), the Logical Memory Story A from the Wechsler Memory Scale (WMS), (Wechsler, 1988), and the Paired Associate Learning test from the Cambridge Neuropsychological Test Automated Battery (CANTAB) (Robbins et al., 1994), (3) one test of executive function: the Trail Making Test (TMT) (Reitan, 1958), and (4) two tests of language: the total score on the Controlled Word Association test for category and letter fluency (Benton and Hamsher, 1976), and the Graded Naming Test from the CANTAB (Robbins et al., 1994).

\section{MRI Acquisition}

MRI images were acquired on a 3.0 Tesla (3T) scanner (Philips Medical Systems, Best, The Netherlands) at the F.M. Kirby Research Center for Functional Brain Imaging at the Kennedy Krieger Institute. At each scanning session, a Magnetization Prepared Rapid Gradient Recalled Echo (MPRAGE) scan and a DTI scan was acquired. The MPRAGE scan was conducted according to the protocol of the Alzheimer's Disease Neuroimaging Initiative (ADNI) (Jack et al., 2008). The current report will focus on the DTI imaging only.

DTI images were acquired using a SENSE head coil on the 3T scanner, equipped with Dual Quasar gradients (up to $80 \mathrm{mT} / \mathrm{m}$ ). For acquisition, an eight-element arrayed RF coil, converted to six-channel to be compatible with the six-channel receiver, was used. For DTI acquisitions, a single-shot spin echo - echo planar sequence (SE-EPI) was used, with diffusion gradients applied in 32 non-collinear directions and $b=700 \mathrm{~s} / \mathrm{mm}^{2}$. Five additional reference images with least diffusion weighting $\left(b=33 \mathrm{~s} / \mathrm{mm}^{2}\right)$ were also acquired. Fifty-sixty axial slices were 
acquired to cover the entire hemisphere and the cerebellum, parallel to the AC-PC line. The field of view, the size of the acquisition matrix, and the slice thickness were $212 \times 212 \mathrm{~mm} /$ $96 \times 96 / 2.2 \mathrm{~mm}$. Other imaging parameters were: TR > 7,000 ms and TE $=80 \mathrm{~ms}$; and SENSE reduction factor $=2.5$. To improve the signal-to-noise ratio, two datasets were acquired, leading to a total acquisition time of 7 minutes. It should be noted that the 'real' brain orientation inside the scanner does not affect the oblique slice because the gradient table is dynamically rotated on the oblique slice angles in such a manner that the " $\mathrm{X}$ gradient' is always $\mathrm{X}$ (right-left) of the image.

\section{DTI Data Processing}

The DTI datasets were transferred to a personal computer running a Windows platform and were processed using DtiStudio (mri.kennedykrieger.org or www.DtiStudio.org) (Jiang et al., 2006). Images were first realigned by affine transformation using Automatic Image Registration (Woods et al., 1998), in order to remove any potential small bulk motion and Eddy-current distortion. The six elements of the diffusion tensor were calculated for each pixel using multivariant linear fitting. After diagonalization, three eigenvalues and eigenvectors were obtained. For the anisotropy map, fractional anisotropy (Bozzali et al., 2002) was used (Pierpaoli and Basser, 1996). The eigenvector (v1) associated with the largest eigenvalue was used as an indicator for fiber orientation. A 24-bit color-coded orientation map was created by assigning red, green, and blue channels to the $\mathrm{x}$ (right-left), $\mathrm{y}$ (anterior-posterior), and $\mathrm{z}$ (superior-inferior) components of the $\mathrm{v} 1$ and its intensity was modulated by FA.

\section{DTI Regions of Interest}

Protocols were developed to identify specific fiber tracts and to manually delineate eight regions of interest (ROI) within the fiber tracts using the in-house software MriStudio/ RoiEditor (www.MriStudio.org or mri.kennedykrieger.org).

The selection of the eight ROIs was accomplished by using both the DTI color maps and the FA images generated by the software. The appropriate slice on which the ROI was identified was chosen by using both the color maps and anatomical landmarks from the FA maps, for consistent slice identification. The ROIs were then drawn manually, using standardized guidelines based on location, color, and size.

The eight ROIs from four fiber tracts were identified as follows (Fig. 1): 1) fornix: the body of the fornix drawn in two adjacent axial slices (FX1 and FX2) using the ventral midbrain and splenium of the corpus callosum as anatomic landmarks; 2) cingulum bundle: inferior cingulum (CG1) at the same axial slice as the cerebral penduncles; the posterior portion of the cinglum bundle (CG2 and CG3) on the same axial slices as the body of the fornix; the anterior portion of the cingulum bundle (CG4) identified in a coronal slice at the level of the anterior commissure; 3) splenium: the mid-sagittal slice of the splenium (Kalus et al.), identified as the enlarged, caudal-most region of the corpus callosum; and 4) cerebral peduncles: the cerebral peduncles (CP) identified on an axial slice just inferior to the decussation of the superior cerebellar peduncles (the latter region was included as a 'control' region, since no changes in this region were anticipated).

The inter-rater reliability of the protocol described above was assessed by having two independent operators (MMM, NAK) manually draw the eight ROIs on the same set of 10 DTI scans. The intra-class correlation of the ROIs ranged from $0.82-0.95$, with a mean of 0.87 . The same two raters completed the ROI analysis on all of the subjects in the present study, blind to the diagnosis. 
With the exception of the splenium and fornix, all ROIs were drawn on both the right and left hemispheres. When longitudinal data were analyzed, slices were chosen by comparing subsequent images to previously analyzed scans from the same subject and choosing the slice that most closely corresponded to that chosen at the previous visit.

\section{Statistical Analysis}

The demographic and health-related characteristics were examined across diagnostic groups using Fischer's Exact Test for dichotomous variables and ANOVA for continuous variables with t-tests for pairwise comparisons when there was a significant $(\mathrm{p}<0.05)$ group difference. Generalized Estimating Equations (GEE) (Zeger et al., 1988) were used to analyze the baseline and 3-month longitudinal measurements. For group (NC, MCI, AD) comparisons of the DTI measures and the clinical and cognitive measures, Wald tests of regression coefficients were used. Longitudinal data techniques are adopted here in order to handle correlation for repeated data measured from the same subject. In the GEE analysis, an exchangeable working correlation structure was used to handle correlated measurements within subjects. Robust variance estimates were included because they guarantee that the inferences are valid in a large sample, even where the assumptions on the working correlation structure are misspecified.

Covariates for analyses incorporating the DTI measures included baseline age and the number of voxels in the ROI. Covariates for analyses incorporating the clinical and cognitive measures included baseline age and years of education. Partial correlation coefficients were used to examine the correlation between the DTI ROIs and cognitive test scores, adjusting for baseline age, years of education, and number of voxels in each ROI. All the techniques used in the GEE analysis are under a semiparametic model and do not require normality assumptions in measurements. Since some of the DTI measures were obtained from both the right and left hemispheres (i.e., CG and CP), each side was initially examined separately. As there was little difference in the results, the FA of the two sides were averaged for the analyses presented here. The a priori $\mathrm{p}$-value was set at $\mathrm{p}<0.05$. All analyses were conducted using STATA Version 10.0 (StataCorp, College Station, TX).

\section{Results \\ Subject Characteristics}

The baseline demographic, health and clinical characteristics of the subjects (Table 1) were compared across diagnostic groups using Fisher's Exact test for categorical variables and ANOVAs for continuous variables (with t-tests for pairwise comparison when $\mathrm{p}<0.05$ ). There were no demographic differences between the groups with regards to age, sex, race, and education. In addition, the prevalence of vascular factors such as hypertension, hypercholesterolemia, and heart attack, did not differ between the groups. As expected, the $\mathrm{AD}$ group was more likely to be taking a dementia medication and had markedly lower scores across neuropsychological tests compared to $\mathrm{MCI}$ and $\mathrm{NC}(\mathrm{p}<0.001)$. The MCI group also had significantly $(\mathrm{p}<0.05)$ worse mean scores compared to the NC groups for the CDR, MMSE, CVLT immediate and delayed recall and Wechsler Story A-immediate and delayed recall. At baseline, there were $2 \mathrm{AD}$ participants whose DTI data could not be processed. At 3 months, $1 \mathrm{MCI}$ withdrew, $1 \mathrm{AD}$ withdrew, and 1 additional $\mathrm{AD}$ participant had data that could not be processed. Those with missing DTI data at baseline were not the same as those with missing data at 3 months. Thus, all participants were included in cross-sectional analyses when data were available. Longitudinal analyses consisted of $25 \mathrm{NC}, 24 \mathrm{MCI}$, and $21 \mathrm{AD}$.

\section{Baseline Group Differences in FA for the Eight ROls}

Using GEE methods and calculating the cross-sectional associations, there were three ROIs that differed at baseline between the $\mathrm{AD}$ and $\mathrm{NC}$ groups, controlling for age and number of voxels. Compared to NC, AD subjects had lower mean FA in FX1 (0.444 vs. 0.512, p=0.008), 
FX2 ( 0.430 vs. $0.499, \mathrm{p}=0.026$ ), and CG4 ( 0.409 vs. $0.439, \mathrm{p}=0.031)$. Compared to the MCI subjects, the AD cases also had lower mean FA at baseline for FX1 ( 0.444 vs. $0.503, \mathrm{p}=0.025$ ), FX2 ( 0.430 vs. $0.476, \mathrm{p}=0.026)$, CG4 ( 0.409 vs. $0.443, \mathrm{p}=0.031)$, as well as for SP (0.606 vs. 0.632, $\mathrm{p}=0.042$ ) (see Table 2 \& Fig. 2).

There were no cross-sectional differences in mean FA between the NC and MCI group. However, the MCI group varied substantially in degree of impairment. We therefore divided the group on the basis of clinical severity, based on the CDR-SB, as has been done previously (Daly et al., 2000). One subgroup (MCI1) consisted of 12 individuals with CDR-SB of 0.51.0; the other subgroup (MCI2) consisted of 13 individuals with a CDR-SB of 1.5-3.5). There were significant differences in FX2 at baseline between the MCI-2 subgroup and the NC $(0.445$ vs. $0.499, \mathrm{p}<0.001)$. There was also a significant difference for FX1 between MCI-1 and the normal controls ( 0.536 vs. $0.512 \mathrm{p}=0.02)$ (Table 3$)$.

\section{DTI FA Changes Between Baseline and Three Months}

An assessment of differential change in FA between baseline and 3 months showed that almost all of the ROIs were stable over the three-month interval (Table 4). The three ROIs that were significantly different between the NC and AD cases at baseline (FX1, FX2 and CG4) were also similarly lower in the AD vs. NC group at 3 months, with the exception of FX1, which did not reach significance at the $\mathrm{p}=0.05$ level $(0.466$ vs. $0.515, \mathrm{p}=0.093)$. The $\mathrm{AD}$ cases also continued to have lower mean FA compared to the MCI cases for FX1, FX2, CG4, and SP at 3 months. Likewise, the significant difference between the NC group and MCI2 subgroup for FX2 was also present at 3 months (Table 3). The difference between the NC group and the MCI1 subgroup for FX1 was, however, not maintained at 3 months. The only region that showed a significant decline between baseline and 3 months was the CG4 region, for the comparison of the $\mathrm{NC}$ vs $\mathrm{MCI}$ group $(\mathrm{b}=-0.027, \mathrm{p}=0.026)$.

\section{Neuropsychological Changes Between Baseline and Three Months}

The clinical diagnosis of all participants between baseline and 3 months remained the same. Differences in the neuropsychological test scores at baseline and 3 months are presented in Table 5. As at baseline, there were significant cross-sectional group differences $(\mathrm{p}<0.05)$ for all neuropsychological tests at 3 months. In longitudinal analyses the AD group, compared to the NC group, performed worse on the MMSE, CVLT long-delay free recall, and Wechsler Memory Scale Immediate and Delayed Recall (Table 5, $\mathrm{p}<0.05$ ). However, this difference was due to a better performance in the NC group between 0-3 months, likely due to a practice effect, rather than a worsening in performance for the $\mathrm{AD}$ group. There were no differences between the $\mathrm{NC}$ and MCI groups over time.

\section{Correlations between DTI and Neuropsychological Performance}

Correlations between the DTI measures and the clinical and cognitive scores were examined among the patient groups (i.e. MCI and $\mathrm{AD}$ ) in order to better interpret disease progression. The FX1, FX2 and CG4 were correlated across all of the cognitive measures at baseline (Table 6), with lower FA in these ROIs corresponding to worse performance, after controlling for age, education and number of voxels. The SP was inversely correlated with the clinical measures [CDR-Rating $(r=-0.263, p=0.081)$ and CDR-Sum of Boxes $(r=-0.321, p=0.032]$, but not with any of the cognitive measures.

\section{Discussion}

The present findings demonstrate significant cross-sectional differences in fiber tract integrity (as measured by FA) including 1) for AD vs. NC: reduced FA in the fornix and the anterior portion of the cingulum bundle; 2) for AD vs. MCI: reduced FA in the fornix, the anterior 
portion of the cingulum, and the splenium; and 3) for MCI vs. NC: Cross-sectional differences for the fornix, but only among the most impaired subgroup of MCI cases (i.e. MCI2 vs. NC). Over a 3-month interval, during which the subjects were clinically stable, only one region showed a significant decrease in FA, the anterior portion of the cingulum bundle. This decrease was observed only for the MCI group relative to the NC group. Lastly, there were strong crosssectional correlations between the fornix and anterior portion of the cingulum bundle and all neuropsychological tests.

The primary finding of the study pertains to the importance of differences in fiber integrity in the fornix among NC, MCI cases and AD patients. The only other previous study with comparable findings evaluated presymptomatic PS1 mutation carriers vs. non-carriers (Ringman et al., 2007). Thus, these data extend that finding to an older age range, and in particular to individuals with amnestic MCI as well as late onset AD. The strength of this finding is emphasized by the fact that the FA values in the fornix were strongly correlated with all of the cognitive measures (e.g., CVLT), as well as with measures of disease severity (e.g., CDR-SB). These results are also consistent with the known neurobiology of AD since the fornix is a predominant outflow tract of the hippocampus. It has been hypothesized that the intracortical (e.g. limbic) projecting fibers are preferentially affected early in the course of AD) while extracortical fiber tracts are relatively preserved (Braak and Braak, 1996; Hyman et al., 1984; Teipel et al., 2007), and the present findings further support this theory.

As noted above, there were no differences in FA across ROIs for the MCI vs. NC group. Due to the variability in the MCI group, participants were subgrouped based on their CDR-SB, as has been done previously (Daly et al., 2000). With these subgroups, there were differences only in the fornix for MCI-1 vs. AD and MCI-2 vs. NC. These findings further support the fornix being an early marker of disease progression. Future studies will determine if this region is a sensitive indicator of disease progression over time.

DTI studies of MCI and AD patients have varied greatly in ROIs examined. Recent crosssectional studies have reported white matter abnormalities in the temporal lobes (Fellgiebel et al., 2004; Head et al., 2004; Kalus et al., 2006; Takahashi et al., 2002; Xie et al., 2006) and other posterior lobe regions (Fellgiebel et al., 2004; Head et al., 2004; Takahashi et al., 2002), posterior corpus collosum (Takahashi et al., 2002), left centrum semiovale (Fellgiebel et al., 2004), and both the anterior (Takahashi et al., 2002) and posterior (Ding et al., 2008; Takahashi et al., 2002; Zhang et al., 2007) cingulum. While we did not directly examine many of these ROIs, our results generally agree in locality because our strongest findings were with the fornix. Interestingly, while previous studies with similarly drawn ROIs in the cingulum reported significant group differences in the posterior portion of the cingulum,(Ding et al., 2008; Zhang et al., 2007) we found group differences in the anterior portion. One other study reported a similar finding with lower mean FA in this region for AD patients compared to NC (Takahashi et al., 2002), but another study did not find a difference between groups (Cho et al., 2008). Head et al. (Head et al., 2004) reported age-associated changes in white matter exhibited a roughly anterior to posterior gradient while dementia status was characterized more by posterior changes. There were no mean age differences between our diagnostic groups so the age-associated findings can not explain our current results. Given our strong findings in the anterior portion of the cingulum, additional studies are warranted

The vast majority of ROIs were stable across the 3-month follow-up. This was expected as patients were clinically stable over this short interval and suggests that changes in FA in these regions may be useful as markers of disease severity. However, we did observe a significant reduction in FA over the 3-month interval for the anterior cingulate region in the MCI group relative to the controls. Whether this change is an indicator or predictor of future clinical progression, or resulting from error and an unreliable measurement, will be further investigated 
with additional follow-up of these participants. If this finding is replicated, it would be an important indicator of disease progression and therefore a potential biomarker for clinical trials.

The present study has several advantages including a larger sample size relative to other DTI studies, a well-characterized group of subjects and multiple measures of cognition as well as disease severity. Moreover, it is the first to examine short term longitudinal change in DTI measures among normals, MCI cases and AD patients. One potential limitation of the study is the fact that we did not analyze other measures of white matter or gray matter to determine their relationship to the present findings (apart from an assessment of vascular risks). Moreover, the presence of white matter hyperintensities (WMH) was not considered in the exclusion criteria. While the prevalence of vascular factors including hypertension,

hypercholesterolemia, angina and myocardial infarction, did not vary by group, there still is a possibility that the presence of WMH could partially confound the DTI findings. Another potential limitation is that CSF suppression was not used in the acquisition of the images, which raises the possibility that partial voluming is, at least in part, related to the group differences in regions near the ventricles (e.g., the fornix). Future studies can address this issue.

In conclusion, we found cross-sectional differences in FA between $\mathrm{AD}$ and $\mathrm{NC}$ for the fornix and anterior cingulate. Compared to the MCI group, the $\mathrm{AD}$ group also had lower FA levels in the fornix, anterior cingulate, and splenium. Importantly, while most ROIs were stable over the 3-month follow-up, during which there was no diagnostic change, the FA of the anterior cingulate did significantly decrease in the MCI group relative to the NC group, suggesting that this marker could be a sensitive, early indicator of AD progression. Since these subjects were re-evaluated at both 6 and 12 months we hope to further pursue whether, in fact, this ROI continues to change with disease severity and whether change in other ROIs may also be important predictors of AD progression. Additional analyses will also provide valuable information about the importance of DTI regional measures for characterizing brain changes over a time interval useful for clinical trials.

\section{Acknowledgments}

This research was funded in part by grants from GlaxoSmithKline, the National Institute on Aging (P50-AG005146 and P50-AG 021334) and the National Institute of Research Resources (NCRR, P41-RR15241). NCRR is a component of the National Institutes of Health (NIH). Its contents are solely the responsibility of the authors and do not necessarily represent the official view of NCRR or NIH. Equipment used in this study was manufactured by Philips. Dr. van Zijl is a paid lecturer for Philips Medical Systems and is the inventor of technology that is licensed to Philips. This arrangement has been approved by Johns Hopkins University in accordance with its conflict of interest policies.

\section{References}

Alzheimer's Association. Research consent for cognitively impaired adults: recommendations for institutional review boards and investigators. Alzheimer Dis Assoc Disord 2004;18:171-175. [PubMed: 15494623]

Basser PJ, Jones DK. Diffusion-tensor MRI: theory, experimental design and data analysis - a technical review. NMR Biomed 2002;15:456-467. [PubMed: 12489095]

Beaulieu C, Does MD, Snyder RE, Allen PS. Changes in water diffusion due to Wallerian degeneration in peripheral nerve. Magn Reson Med 1996;36:627-631. [PubMed: 8892217]

Bennett DA, Schneider JA, Bienias JL, Evans DA, Wilson RS. Mild cognitive impairment is related to Alzheimer disease pathology and cerebral infarctions. Neurology 2005;64:834-841. [PubMed: 15753419]

Benton, A.; Hamsher, K. Multilingual Aphasia Examination. University of Iowa; Iowa City: 1976.

Bozzali M, Falini A, Franceschi M, Cercignani M, Zuffi M, Scotti G, Comi G, Filippi M. White matter damage in Alzheimer's disease assessed in vivo using diffusion tensor magnetic resonance imaging. J Neurol Neurosurg Psychiatry 2002;72:742-746. [PubMed: 12023417] 
Braak H, Braak E. Evolution of the neuropathology of Alzheimer's disease. Acta Neurol Scand Suppl 1996;165:3-12. [PubMed: 8740983]

Cho H, Yang DW, Shon YM, Kim BS, Kim YI, Choi YB, Lee KS, Shim YS, Yoon B, Kim W, Ahn KJ. Abnormal integrity of corticocortical tracts in mild cognitive impairment: a diffusion tensor imaging study. J Korean Med Sci 2008;23:477-483. [PubMed: 18583886]

Choi SJ, Lim KO, Monteiro I, Reisberg B. Diffusion tensor imaging of frontal white matter microstructure in early Alzheimer's disease: a preliminary study. J Geriatr Psychiatry Neurol 2005;18:12-19. [PubMed: 15681623]

Cummings JL, Mega M, Gray K, Rosenberg-Thompson S, Carusi DA, Gornbein J. The Neuropsychiatric Inventory: comprehensive assessment of psychopathology in dementia. Neurology 1994;44:23082314. [PubMed: 7991117]

Daly E, Zaitchik D, Copeland M, Schmahmann J, Gunther J, Albert M. Predicting conversion to Alzheimer disease using standardized clinical information. Arch Neurol 2000;57:675-680. [PubMed: 10815133]

Delis DC, Freeland J, Kramer JH, Kaplan E. Integrating clinical assessment with cognitive neuroscience: construct validation of the California Verbal Learning Test. J Consult Clin Psychol 1988;56:123130. [PubMed: 3346437]

Ding B, Chen KM, Ling HW, Zhang H, Chai WM, Li X, Wang T. Diffusion tensor imaging correlates with proton magnetic resonance spectroscopy in posterior cingulate region of patients with Alzheimer's disease. Dement Geriatr Cogn Disord 2008;25:218-225. [PubMed: 18219201]

Duan JH, Wang HQ, Xu J, Lin X, Chen SQ, Kang Z, Yao ZB. White matter damage of patients with Alzheimer's disease correlated with the decreased cognitive function. Surg Radiol Anat 2006;28:150-156. [PubMed: 16614789]

Fellgiebel A, Muller MJ, Wille P, Dellani PR, Scheurich A, Schmidt LG, Stoeter P. Color-coded diffusion-tensor-imaging of posterior cingulate fiber tracts in mild cognitive impairment. Neurobiol Aging 2005;26:1193-1198. [PubMed: 15917103]

Fellgiebel A, Schermuly I, Gerhard A, Keller I, Albrecht J, Weibrich C, Muller MJ, Stoeter P. Functional relevant loss of long association fibre tracts integrity in early Alzheimer's disease. Neuropsychologia 2008;46:1698-1706. [PubMed: 18243252]

Fellgiebel A, Wille P, Muller MJ, Winterer G, Scheurich A, Vucurevic G, Schmidt LG, Stoeter P. Ultrastructural hippocampal and white matter alterations in mild cognitive impairment: a diffusion tensor imaging study. Dement Geriatr Cogn Disord 2004;18:101-108. [PubMed: 15087585]

Folstein MF, Folstein SE, McHugh PR. "Mini-mental state". A practical method for grading the cognitive state of patients for the clinician. J Psychiatr Res 1975;12:189-198. [PubMed: 1202204]

Head D, Buckner RL, Shimony JS, Williams LE, Akbudak E, Conturo TE, McAvoy M, Morris JC, Snyder AZ. Differential vulnerability of anterior white matter in nondemented aging with minimal acceleration in dementia of the Alzheimer type: evidence from diffusion tensor imaging. Cereb Cortex 2004;14:410-423. [PubMed: 15028645]

Huang J, Auchus AP. Diffusion tensor imaging of normal appearing white matter and its correlation with cognitive functioning in mild cognitive impairment and Alzheimer's disease. Ann N Y Acad Sci 2007;1097:259-264. [PubMed: 17413027]

Hughes CP, Berg L, Danziger WL, Coben LA, Martin RL. A new clinical scale for the staging of dementia. Br J Psychiatry 1982;140:566-572. [PubMed: 7104545]

Hyman BT, Van Hoesen GW, Damasio AR, Barnes CL. Alzheimer's disease: cell-specific pathology isolates the hippocampal formation. Science 1984;225:1168-1170. [PubMed: 6474172]

Jack CR Jr, Bernstein MA, Fox NC, Thompson P, Alexander G, Harvey D, Borowski B, Britson PJ, J LW, Ward C, Dale AM, Felmlee JP, Gunter JL, Hill DL, Killiany R, Schuff N, Fox-Bosetti S, Lin C, Studholme C, DeCarli CS, Krueger G, Ward HA, Metzger GJ, Scott KT, Mallozzi R, Blezek D, Levy J, Debbins JP, Fleisher AS, Albert M, Green R, Bartzokis G, Glover G, Mugler J, Weiner MW. The Alzheimer's Disease Neuroimaging Initiative (ADNI): MRI methods. J Magn Reson Imaging 2008;27:685-691. [PubMed: 18302232]

Jiang H, van Zijl PC, Kim J, Pearlson GD, Mori S. DtiStudio: resource program for diffusion tensor computation and fiber bundle tracking. Comput Methods Programs Biomed 2006;81:106-116. [PubMed: 16413083] 
Jicha GA, Parisi JE, Dickson DW, Johnson K, Cha R, Ivnik RJ, Tangalos EG, Boeve BF, Knopman DS, Braak H, Petersen RC. Neuropathologic outcome of mild cognitive impairment following progression to clinical dementia. Arch Neurol 2006;63:674-681. [PubMed: 16682537]

Kalus P, Slotboom J, Gallinat J, Mahlberg R, Cattapan-Ludewig K, Wiest R, Nyffeler T, Buri C, Federspiel A, Kunz D, Schroth G, Kiefer C. Examining the gateway to the limbic system with diffusion tensor imaging: the perforant pathway in dementia. NeuroImage 2006;30:713-720. [PubMed: 16337815]

McKhann G, Drachman D, Folstein M, Katzman R, Price D, Stadlan EM. Clinical diagnosis of Alzheimer's disease: report of the NINCDS-ADRDA Work Group under the auspices of Department of Health and Human Services Task Force on Alzheimer's Disease. Neurology 1984;34:939-944. [PubMed: 6610841]

Medina D, DeToledo-Morrell L, Urresta F, Gabrieli JD, Moseley M, Fleischman D, Bennett DA, Leurgans S, Turner DA, Stebbins GT. White matter changes in mild cognitive impairment and AD: A diffusion tensor imaging study. Neurobiol Aging 2006;27:663-672. [PubMed: 16005548]

Mohs RC, Knopman D, Petersen RC, Ferris SH, Ernesto C, Grundman M, Sano M, Bieliauskas L, Geldmacher D, Clark C, Thal LJ. Development of cognitive instruments for use in clinical trials of antidementia drugs: additions to the Alzheimer's Disease Assessment Scale that broaden its scope. The Alzheimer's Disease Cooperative Study. Alzheimer Dis Assoc Disord 1997;11(Suppl 2):S1321. [PubMed: 9236948]

Mori S, Crain BJ, Chacko VP, van Zijl PC. Three-dimensional tracking of axonal projections in the brain by magnetic resonance imaging. Ann Neurol 1999;45:265-269. [PubMed: 9989633]

Morris JC. The Clinical Dementia Rating (CDR): current version and scoring rules. Neurology 1993;43:2412-2414. [PubMed: 8232972]

Naggara O, Oppenheim C, Rieu D, Raoux N, Rodrigo S, Dalla Barba G, Meder JF. Diffusion tensor imaging in early Alzheimer's disease. Psychiatry Res 2006;146:243-249. [PubMed: 16520023]

Petersen RC. Mild cognitive impairment as a diagnostic entity. J Intern Med 2004;256:183-194. [PubMed: 15324362]

Petersen RC, Morris JC. Mild cognitive impairment as a clinical entity and treatment target. Arch Neurol 2005;62:1160-1163. [PubMed: 16009779]discussion 1167

Petersen RC, Smith GE, Waring SC, Ivnik RJ, Tangalos EG, Kokmen E. Mild cognitive impairment: clinical characterization and outcome. Arch Neurol 1999;56:303-308. [PubMed: 10190820]

Pierpaoli C, Basser PJ. Toward a quantitative assessment of diffusion anisotropy. Magn Reson Med 1996;36:893-906. [PubMed: 8946355]

Reitan, R. Trail Making Test: Manual for administration, scoring and interpretation. Indianapolis: Department of Neurology, Indiana University Medical Center; 1958.

Ringman JM, O’Neill J, Geschwind D, Medina L, Apostolova LG, Rodriguez Y, Schaffer B, Varpetian A, Tseng B, Ortiz F, Fitten J, Cummings JL, Bartzokis G. Diffusion tensor imaging in preclinical and presymptomatic carriers of familial Alzheimer's disease mutations. Brain 2007;130:1767-1776. [PubMed: 17522104]

Robbins TW, James M, Owen AM, Sahakian BJ, McInnes L, Rabbitt P. Cambridge Neuropsychological Test Automated Battery (CANTAB): a factor analytic study of a large sample of normal elderly volunteers. Dementia 1994;5:266-281. [PubMed: 7951684]

Rose SE, Chen F, Chalk JB, Zelaya FO, Strugnell WE, Benson M, Semple J, Doddrell DM. Loss of connectivity in Alzheimer's disease: an evaluation of white matter tract integrity with colour coded MR diffusion tensor imaging. J Neurol Neurosurg Psychiatry 2000;69:528-530. [PubMed: 10990518]

Stahl R, Dietrich O, Teipel SJ, Hampel H, Reiser MF, Schoenberg SO. White matter damage in Alzheimer disease and mild cognitive impairment: assessment with diffusion-tensor MR imaging and parallel imaging techniques. Radiology 2007;243:483-492. [PubMed: 17456872]

Sydykova D, Stahl R, Dietrich O, Ewers M, Reiser MF, Schoenberg SO, Moller HJ, Hampel H, Teipel SJ. Fiber connections between the cerebral cortex and the corpus callosum in Alzheimer's disease: a diffusion tensor imaging and voxel-based morphometry study. Cereb Cortex 2007;17:2276-2282. [PubMed: 17164468] 
Takahashi S, Yonezawa H, Takahashi J, Kudo M, Inoue T, Tohgi H. Selective reduction of diffusion anisotropy in white matter of Alzheimer disease brains measured by 3.0 Tesla magnetic resonance imaging. Neurosci Lett 2002;332:45-48. [PubMed: 12377381]

Teipel SJ, Stahl R, Dietrich O, Schoenberg SO, Perneczky R, Bokde AL, Reiser MF, Moller HJ, Hampel H. Multivariate network analysis of fiber tract integrity in Alzheimer's disease. NeuroImage 2007;34:985-995. [PubMed: 17166745]

Wechsler, D. The Wechsler Adult Intelligence Scale-Revised. Psychological Corporation; New York: 1988.

Woods RP, Grafton ST, Holmes CJ, Cherry SR, Mazziotta JC. Automated image registration: I. General methods and intrasubject, intramodality validation. J Comput Assist Tomogr 1998;22:139-152. [PubMed: 9448779]

Xie S, Xiao JX, Gong GL, Zang YF, Wang YH, Wu HK, Jiang XX. Voxel-based detection of white matter abnormalities in mild Alzheimer disease. Neurology 2006;66:1845-1849. [PubMed: 16801648]

Yesavage JA, Brink TL, Rose TL, Lum O, Huang V, Adey M, Leirer VO. Development and validation of a geriatric depression screening scale: a preliminary report. J Psychiatr Res 1982;17:37-49. [PubMed: 7183759]

Zeger SL, Liang KY, Albert PS. Models for longitudinal data: a generalized estimating equation approach. Biometrics 1988;44:1049-1060. [PubMed: 3233245]

Zhang Y, Schuff N, Jahng GH, Bayne W, Mori S, Schad L, Mueller S, Du AT, Kramer JH, Yaffe K, Chui H, Jagust WJ, Miller BL, Weiner MW. Diffusion tensor imaging of cingulum fibers in mild cognitive impairment and Alzheimer disease. Neurology 2007;68:13-19. [PubMed: 17200485] 

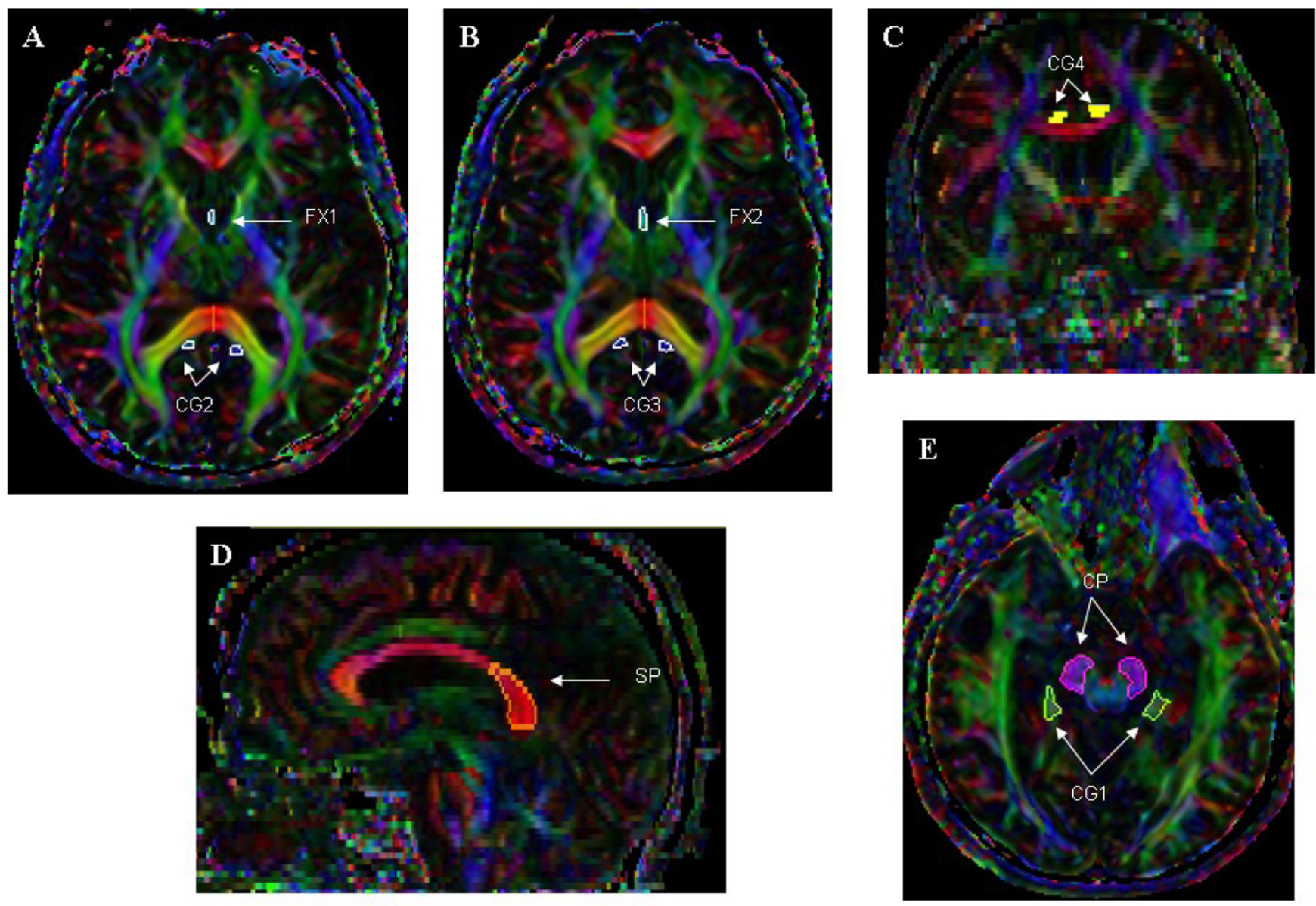

Fig 1.

Illustration of the diffusion tensor imaging regions of interest:A) Fornix 1 (FX1) and Cingulum bundle 2 (CG2); B) Fornix 2 (FX2) and Cingulum 3 (CG3); C) Cingulum 4 (CG4); D) Splenium (Kalus et al.); E) Cerebral Peduncles (CP) and Cingulum 1 (CG1) 
Fornix 1 (FX1)

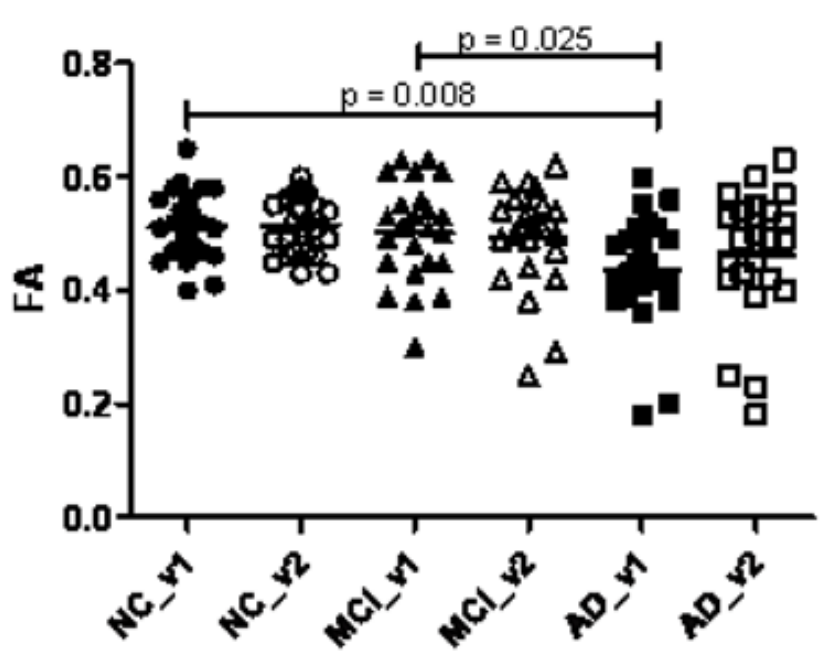

Splenium (SP)

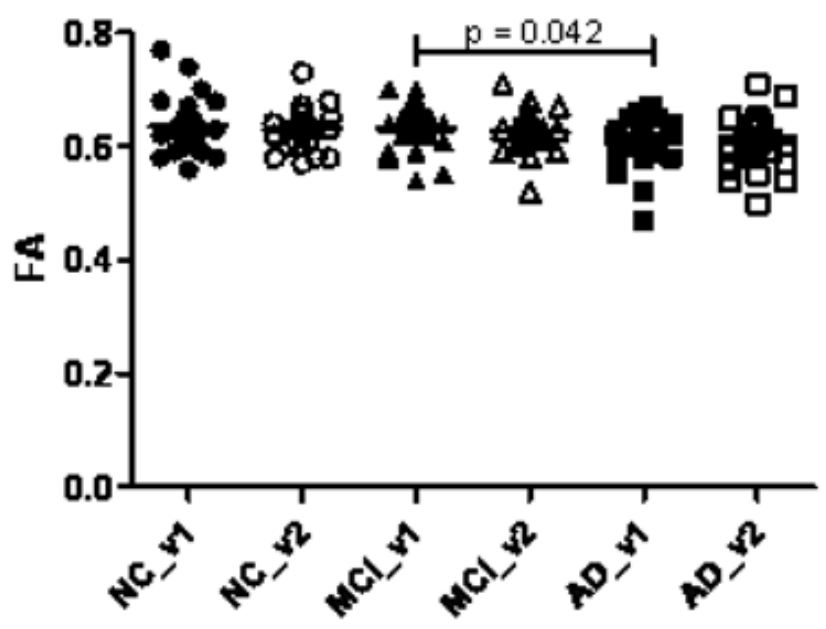

Fornix 2 (FX2)

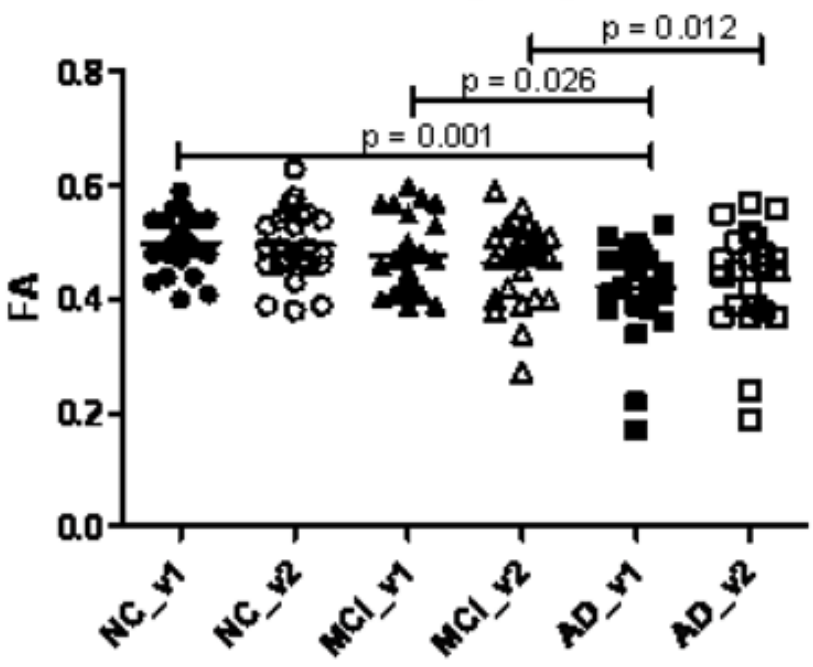

Cingulum 4 (CG4)

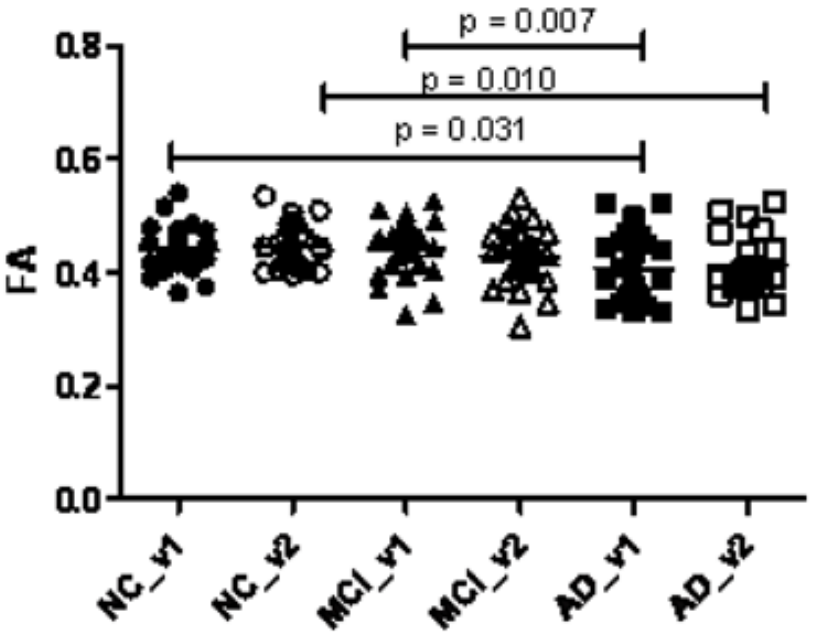

Fig. 2.

Comparison of diffusion tensor imaging regions of interest among groups at baseline (v1) and 3 months (v2). NC = Normal Control; $\mathrm{MCI}=$ Mild Cognitive Impairment; $\mathrm{AD}=$ Alzheimer's disease. Lines with $p$-values indicate significant $(\mathrm{p}<0.05)$ group differences. 


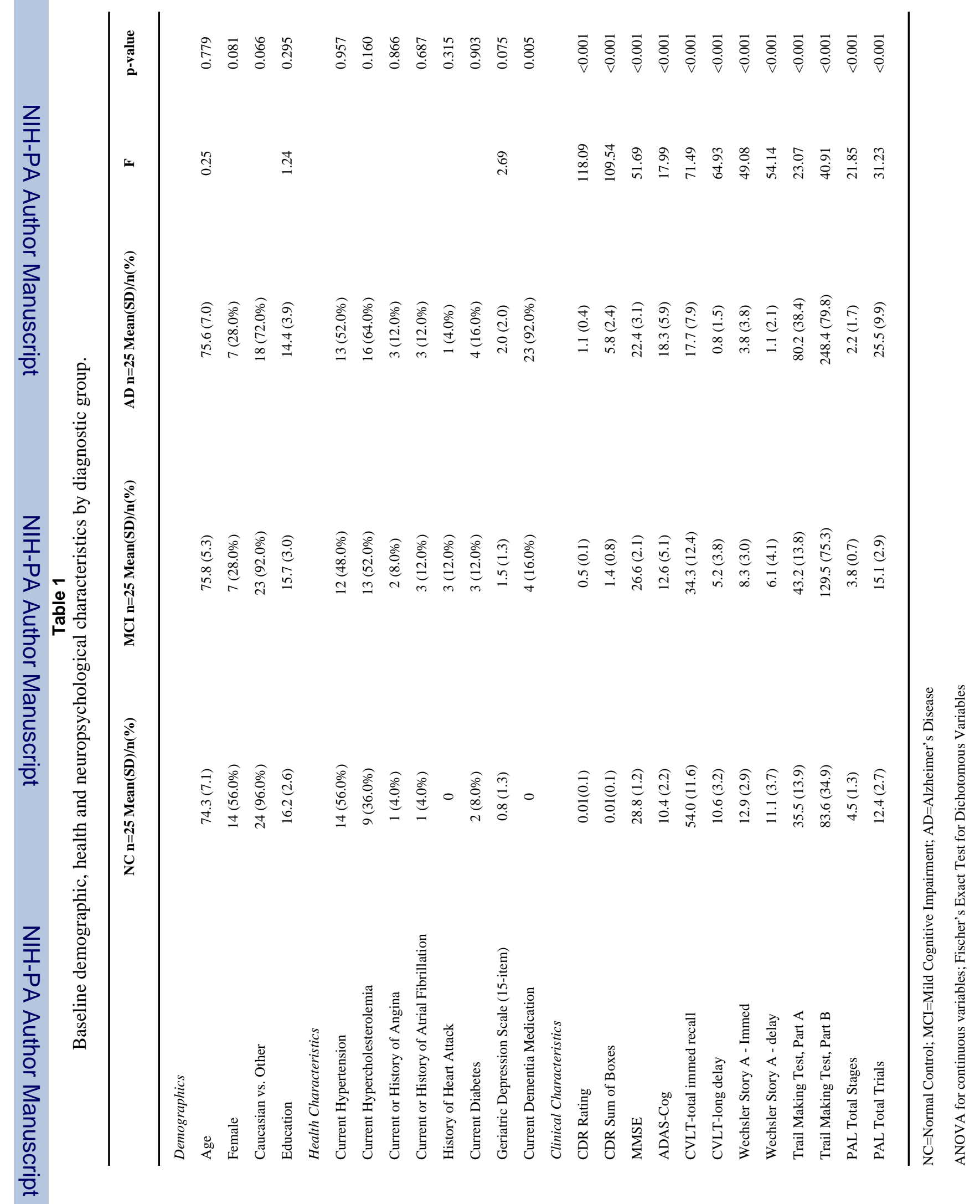

Neuroimage. Author manuscript; available in PMC 2010 May 15. 


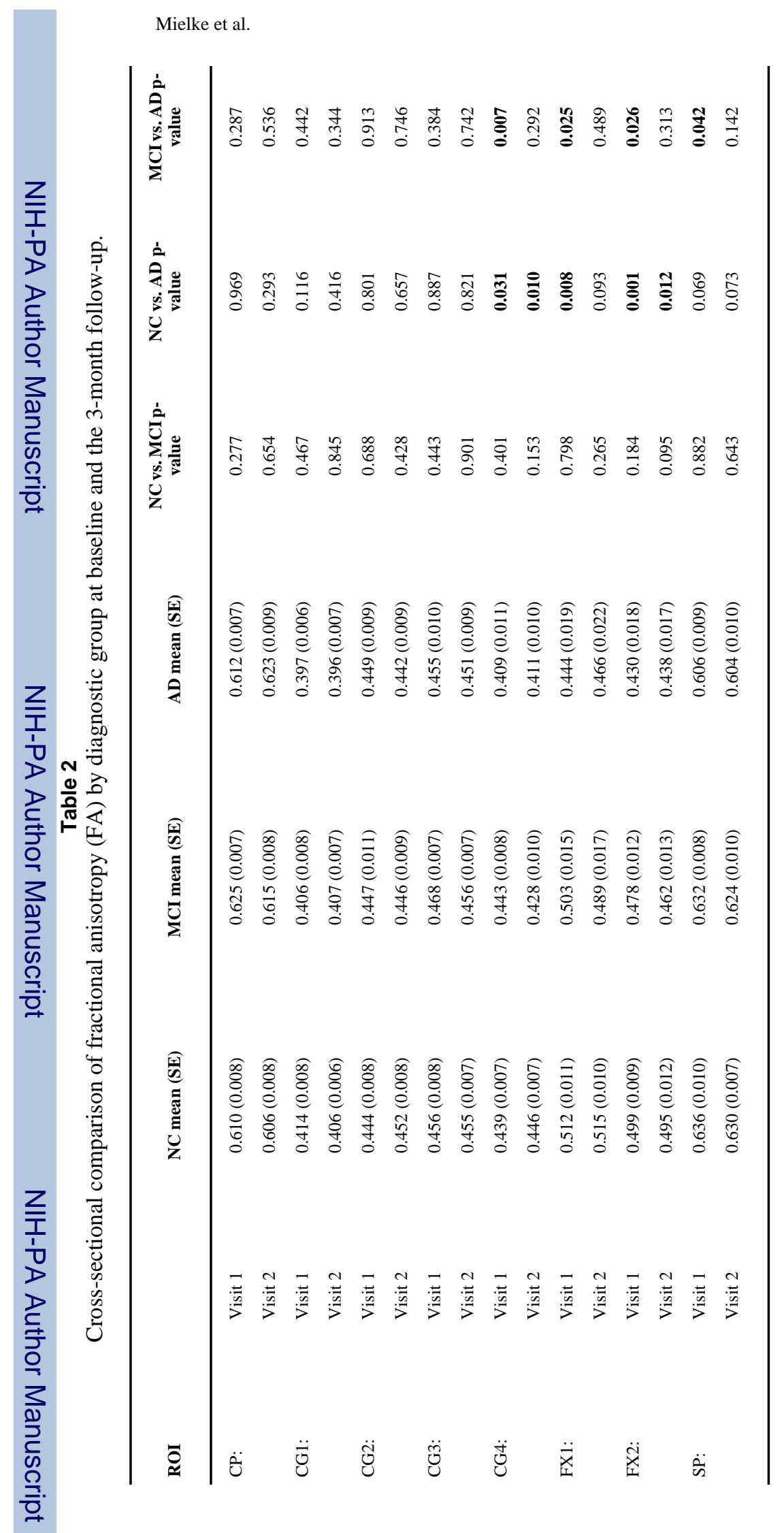


Mielke et al.

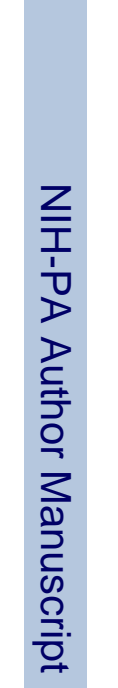

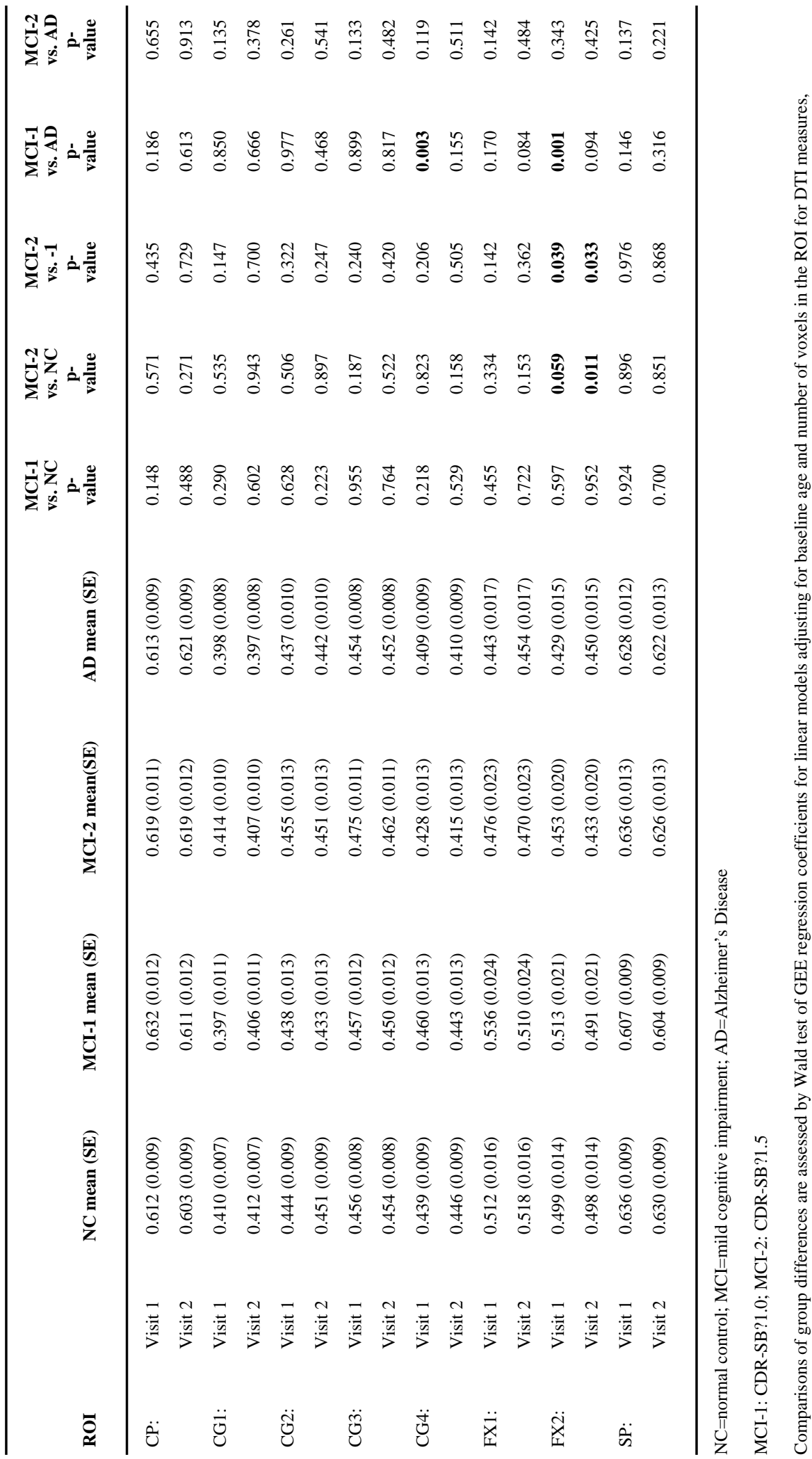

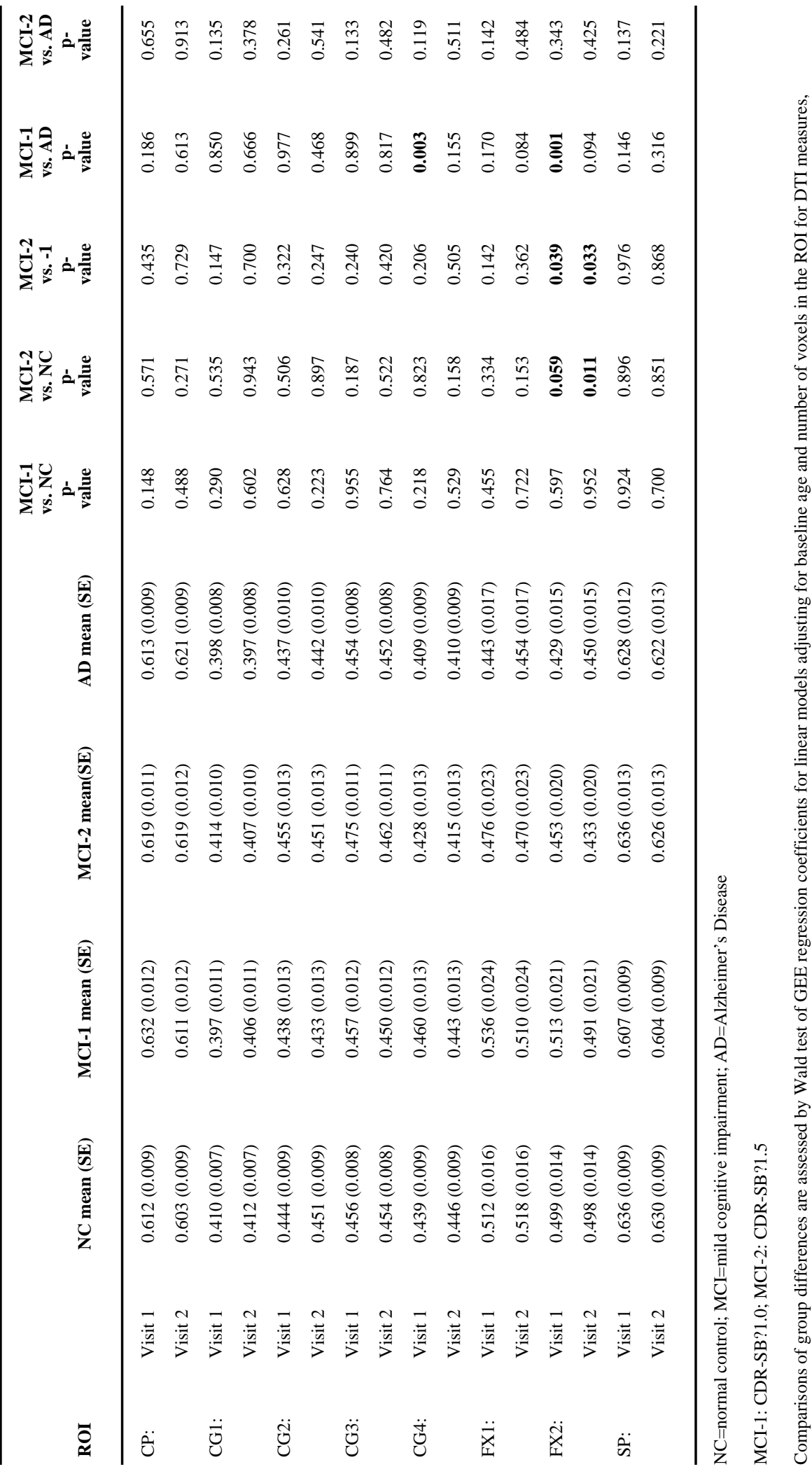

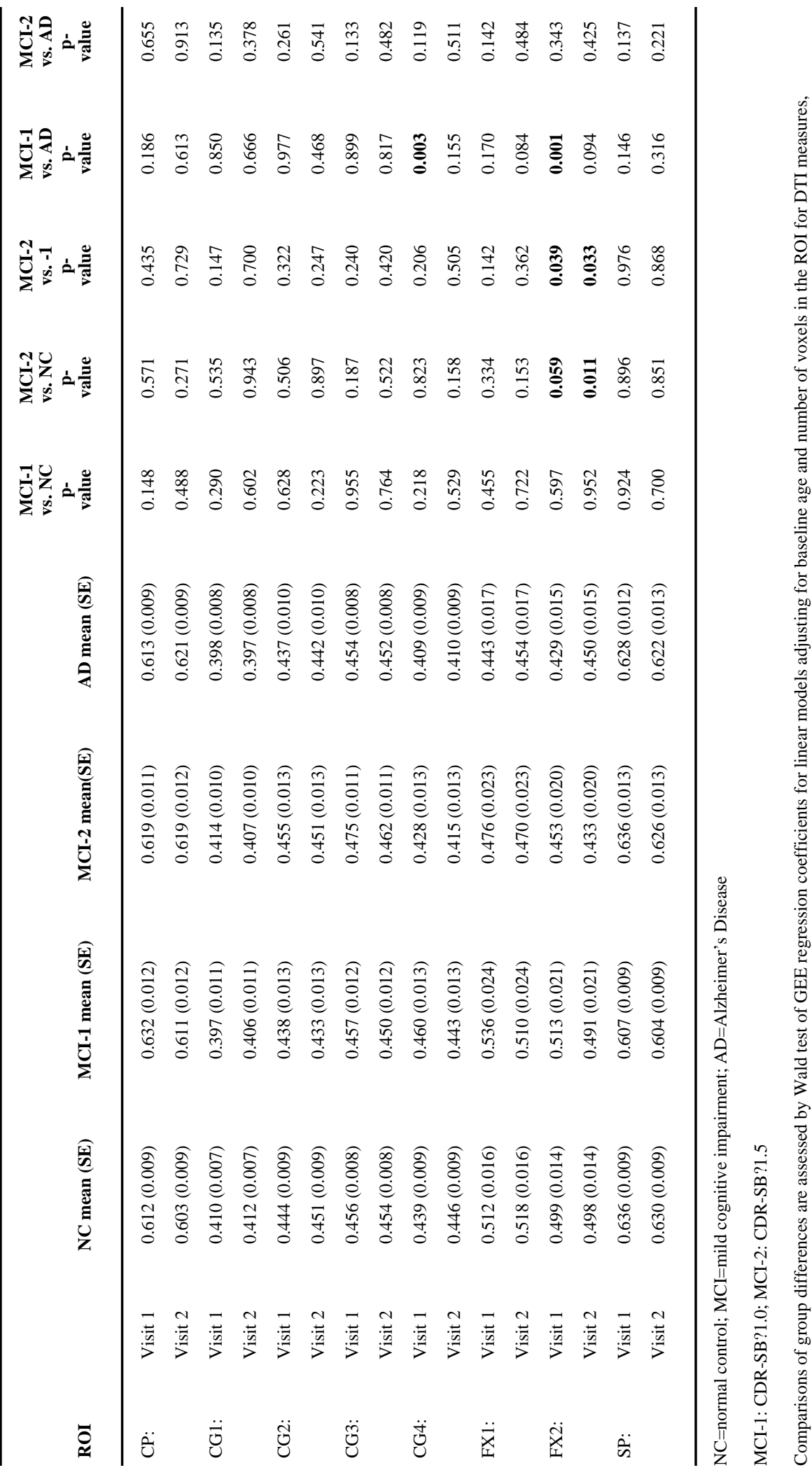

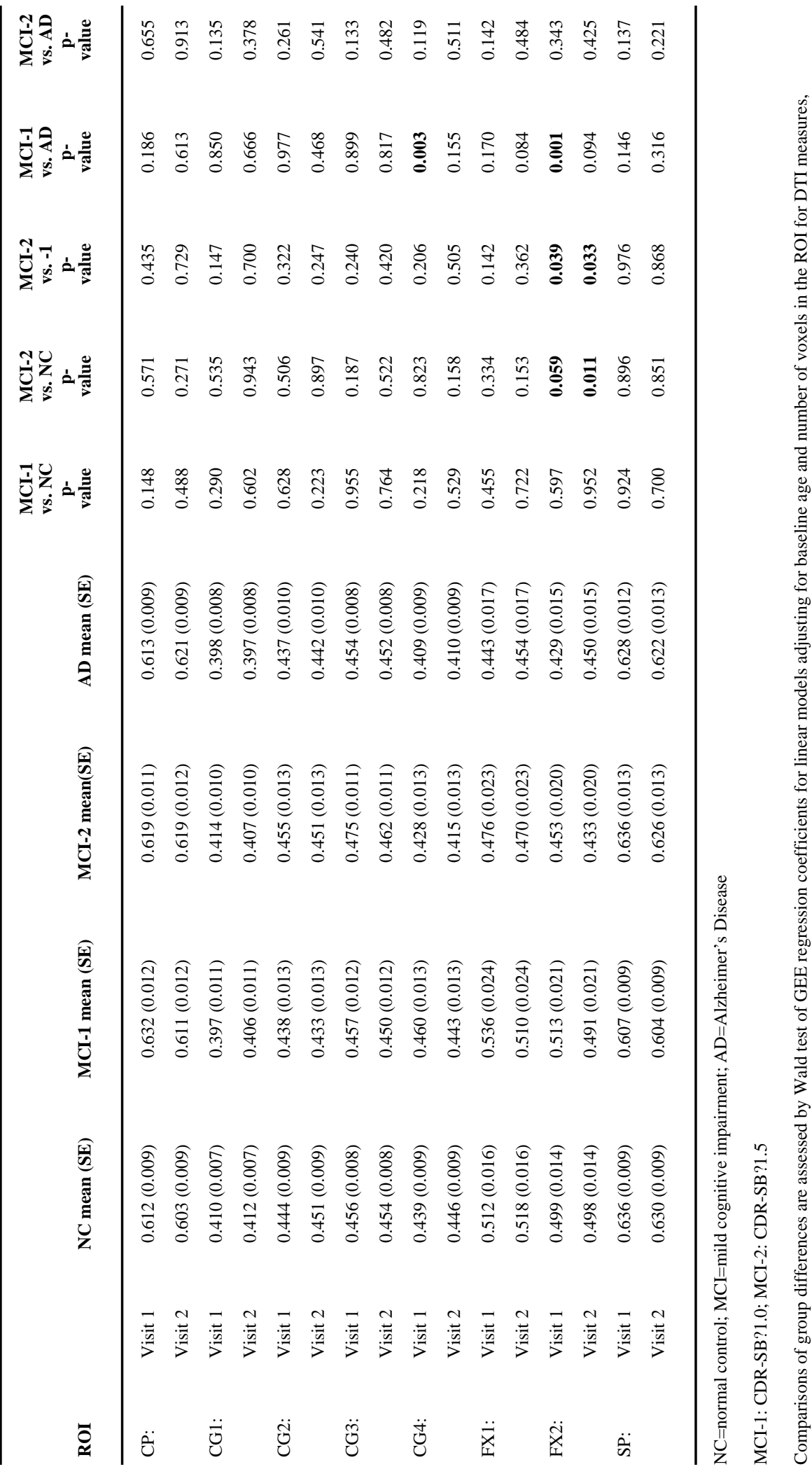

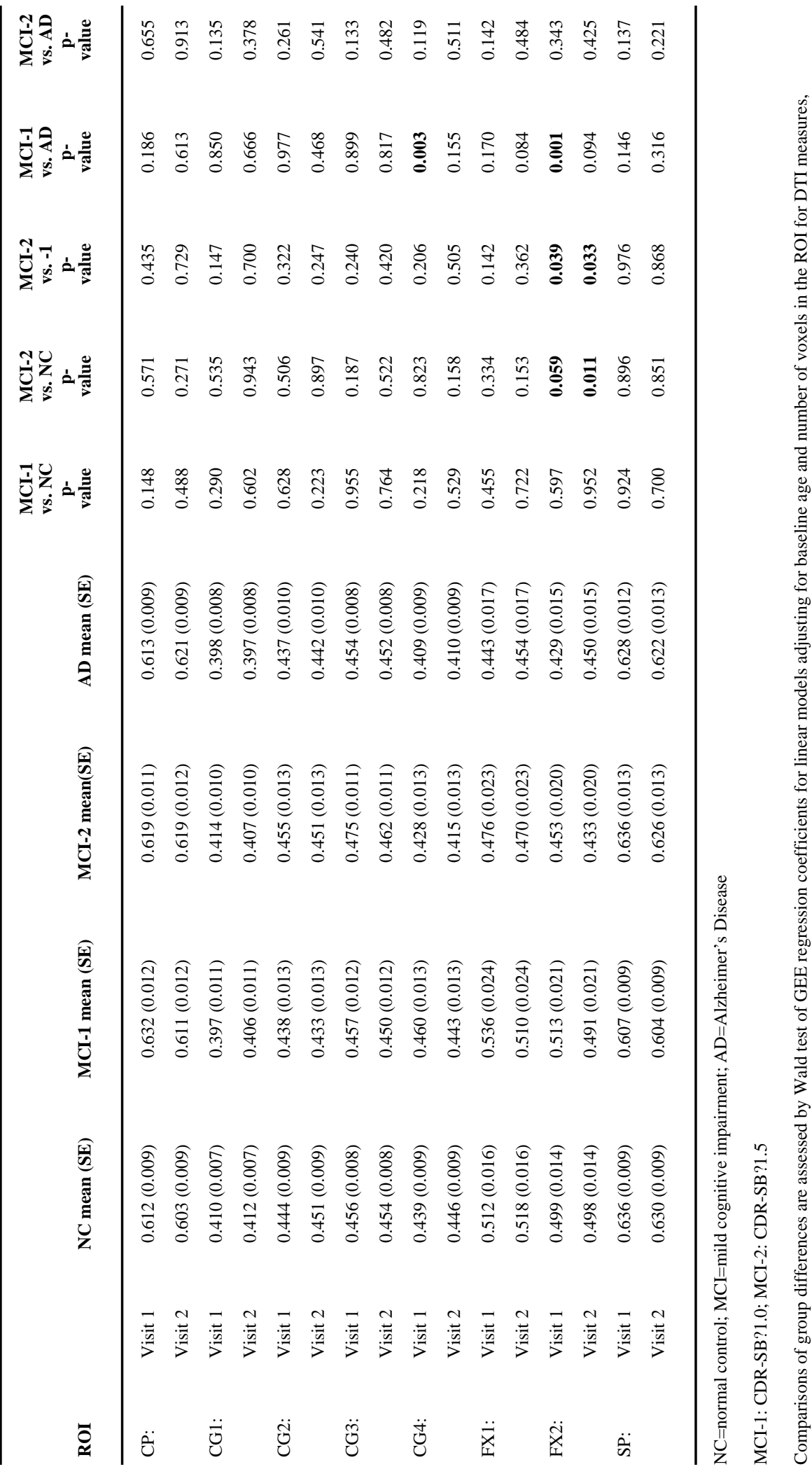

政 


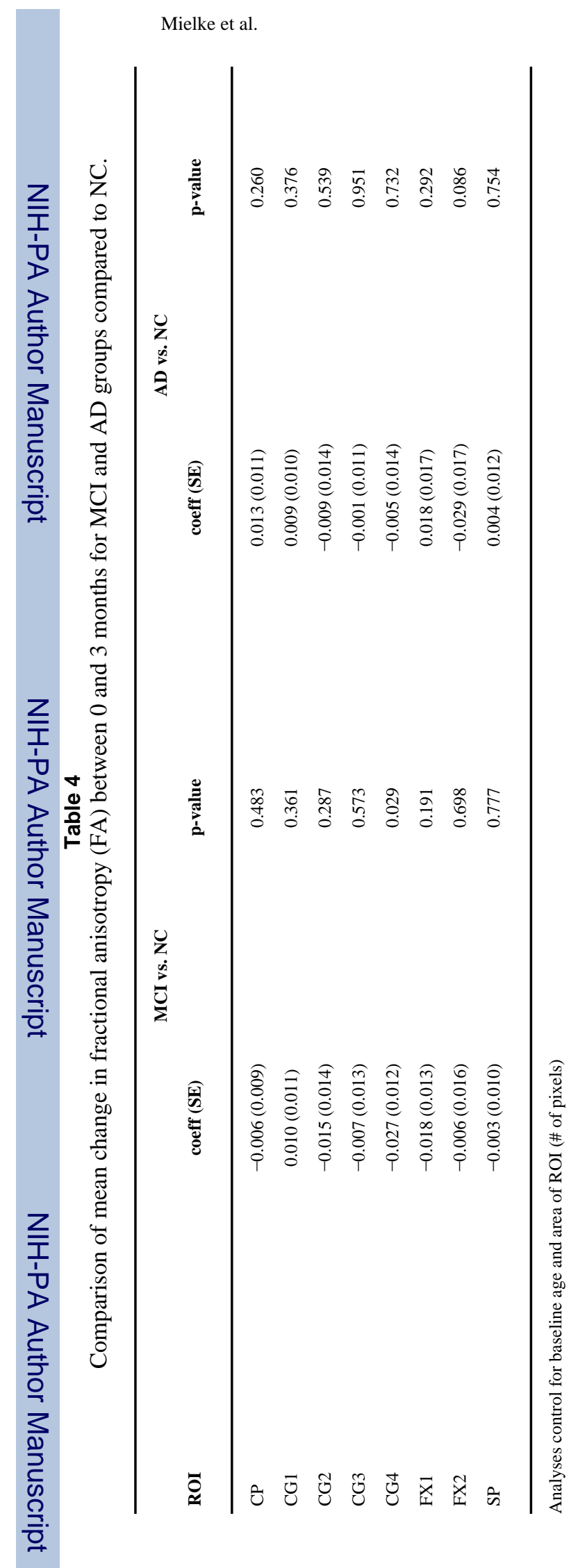

Neuroimage. Author manuscript; available in PMC 2010 May 15. 


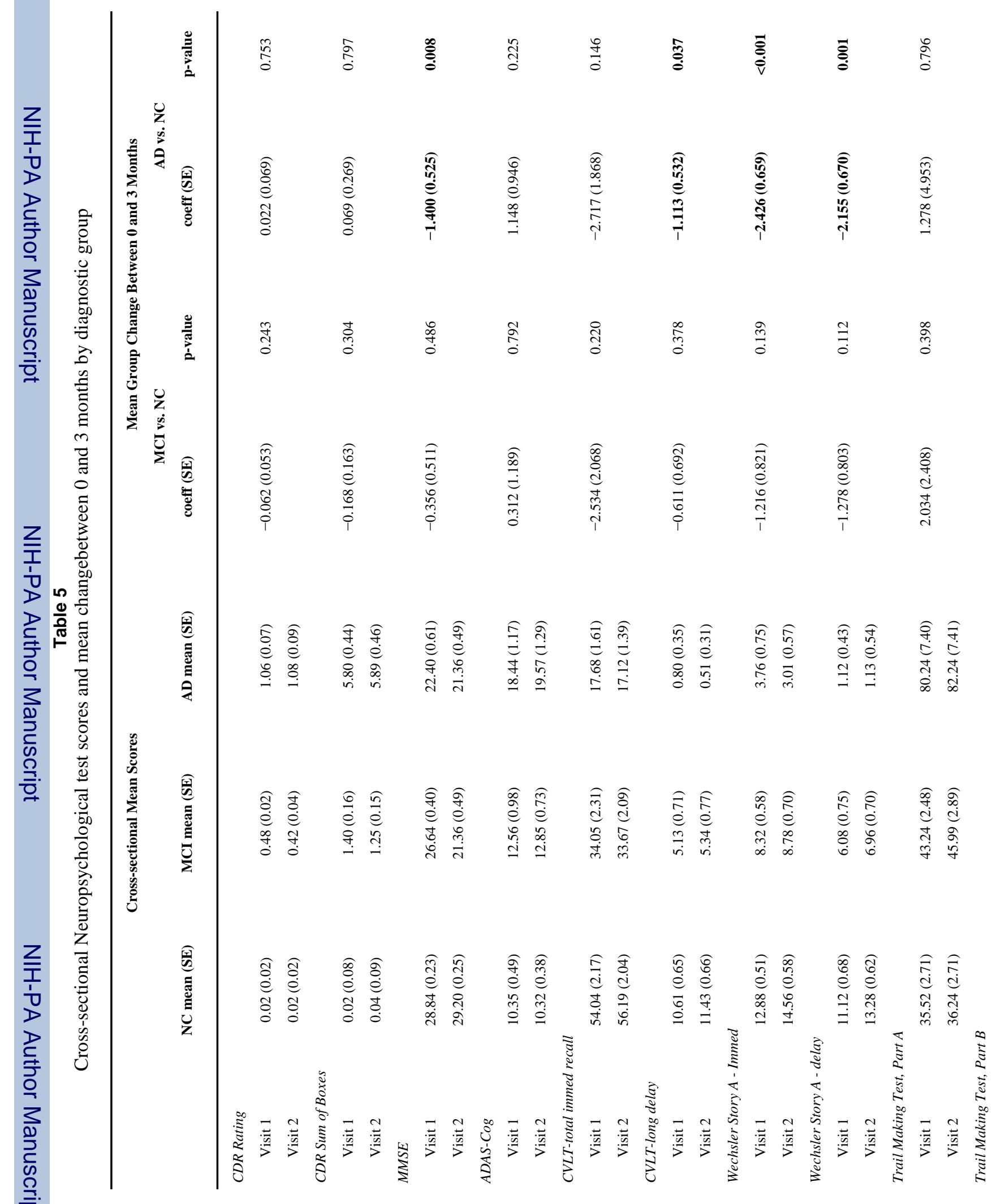

Neuroimage. Author manuscript; available in PMC 2010 May 15. 


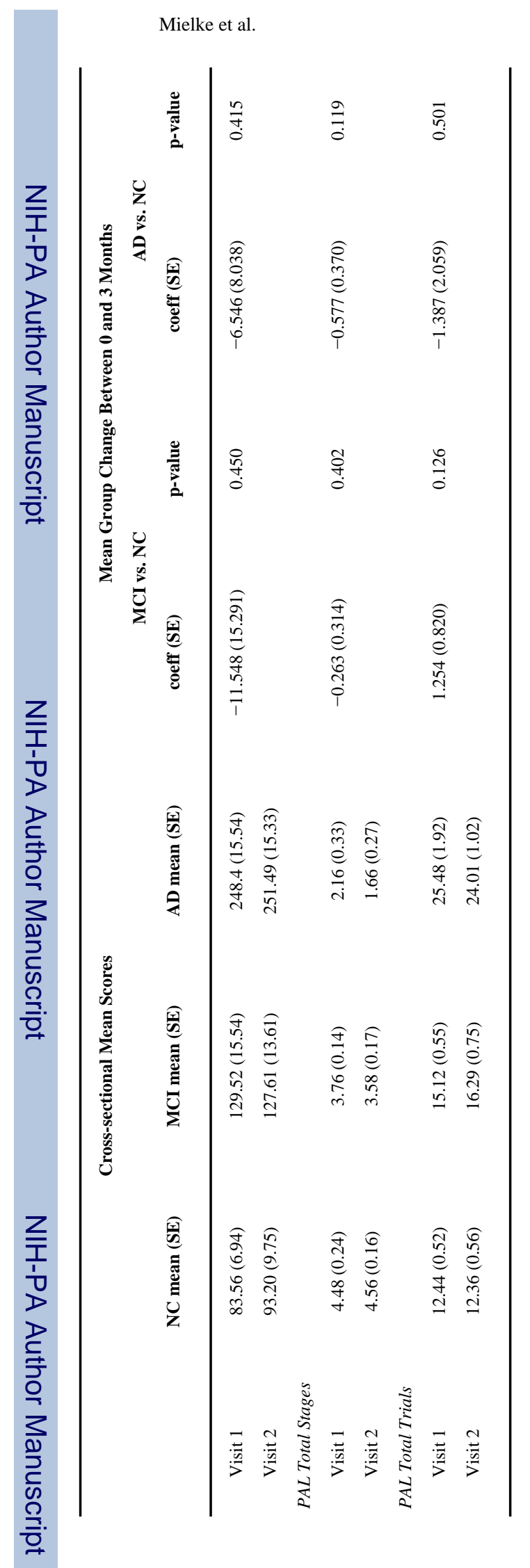

Neuroimage. Author manuscript; available in PMC 2010 May 15. 


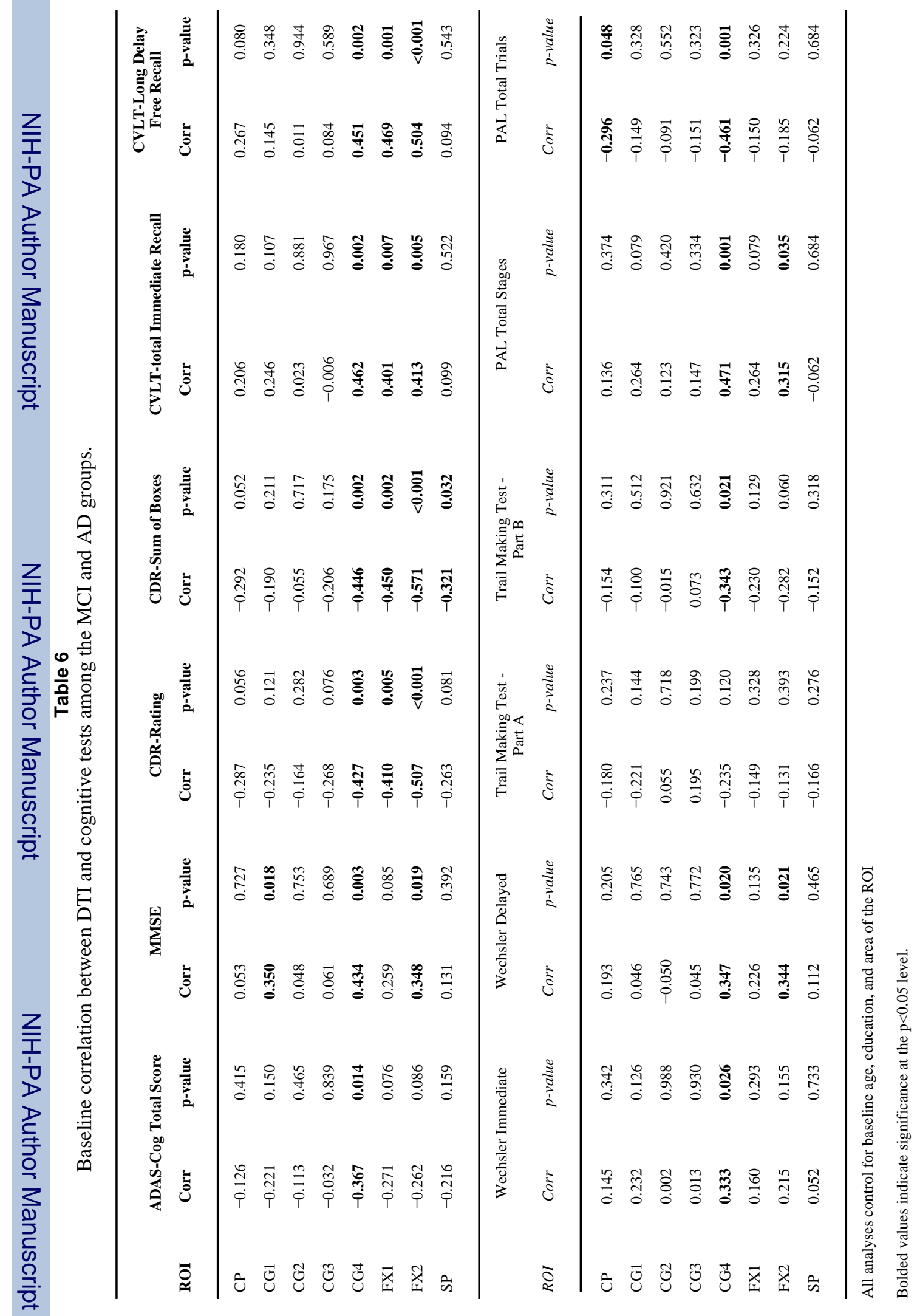

